\title{
TOWARDS A COMMUNITY OF PRACTICE OF A LEADERSHIP MODEL FOR THE RESEARCH UNIVERSITY
}

\author{
*Stephen E. Cross \\ *Nassim Jafari Naimi \\ Georgia Institute of Technology
}

\begin{abstract}
A leadership model used within a major research university in the United States is described. The model integrates concepts about servant and adaptive leadership. Research universities are inherently flat organizations with key peer leadership roles invested in the faculty. The fact that such organizations are undergoing fundamental change (e.g., the expectation to generate increased economic impact from sponsored research) complicates those selected for senior leadership positions. Leaders must anticipate the need to change and do so proactively while serving those throughout the organization. Alignment of vision and strategy, culture and beliefs, processes, plans, people, and desired outcomes is a critical success factor. Senior leadership must consistently and effectively communicate the vision and strategy (i.e., why the organization does what it does) and inspire a sense of urgency to focus the organization on desired results. Specific leadership models and behaviours are examined that are useful in guiding such change. The paper discusses the use of this leadership model within one research university and then explores peer approaches for encouraging wide spread adoption and use of the model. In particular, the use of leadership stories both positive and negative - is currently being explored as a means to support a community of practice.
\end{abstract}

Keywords: Leadership; Organization Adaptation; Innovation; Strategic Management, Research University

\section{INTRODUCTION}

The work reported in this paper explores principles for strategic leadership based on a model for organizational adaptation described earlier in Cross (2013a). A key observation is that organizations that successfully adapt have (1) vertical alignment between vision, mission, and strategy with the beliefs and culture of the organization and (2) horizontal alignment between how work is done and the results of the work. A further observation is that vertical alignment must precede horizontal alignment. Equally important is a credible leadership style that incentivizes a willingness to change and to focus on desired organizational results. Given a rapidly changing environment and the expectations of sponsoring organizations such change must occur with a sense of urgency. The work reported here is part of an overall research program intended to codify a set of actionable principles in a staged process model to guide organizational adaptation and to enhance strategic leadership. This paper reviews the prominent leadership models and styles and then proposes key principles for strategic leadership. The authors' research university is used to illustrate how these principles are applied and taught.

This work is conducted at the Georgia Institute of Technology (Georgia Tech) in Atlanta, Georgia, USA. As discussed in Katz and Bradley (2013) and Clark (2013), research universities are increasingly the nucleus of growth and impact for regional, urban-based innovation ecosystems. In fact the mission of such universities beyond education and research is to transition research in order to impact and drive the regional ecosystem. Hage (2011) explores six necessary functions that must exist for the successful innovation ecosystem: fundamental research, applied research, product development, manufacturing process, quality improvement, and extension services. As research universities are increasingly called upon to provide these functions, they must adapt. But adaptation is complicated by the fact that research universities, typical of any knowledge intensive organization, are populated by fiercely independent knowledge creators who exhibit a willingness to participate in overall institutional change programs only when the personal benefit is obvious and positive. 
Such organizations also expect efficient and effective support from various functions such as human resources, finance, and facilities management. Lopez (2012) describes how knowledge workers appreciate that their skills are applied every day and that they are valued by senior leadership. That is, they want to know that what they do is an integral part of the organization's future, that they are surrounded by colleagues who care for them, and that an exciting and credible vision is being communicated by senior leadership.

The paper will proceed with a brief review of pertinent literature followed by an overview of the Georgia Tech Research Leadership Model (GT-RLM) which is used by leaders throughout its research enterprise. This leadership includes senior administrators reporting to the President, associate deans for research; heads of direct support units such as contracting and start-up services; and faculty who lead research groups, centers, and institutes. New work focused on the creation of a community of practice to aid enhancement and to facilitate use of the leadership model is also discussed.

\section{REVIEW OF LITERATURE}

Two oft cited models of leadership are referred to as transactional and transformational as described by Charan, Drotter, and Noel (2007). These are illustrated in Table 1. A transactional model is one in which the roles and responsibilities of people within the organization are clearly defined and routine. Work processes are designed for efficiency and personal innovation is often expected or tolerated. A rewards and punishment

\section{Table 1: Leadership model contrasts}

\begin{tabular}{|c|c|c|}
\hline & Transactional & Transformative \\
\hline Example & Machine shop & Modern factory \\
\hline Characteristics & $\begin{array}{l}\text { Well-developed hierarchical structure and } \\
\text { disciplined processes }\end{array}$ & Open communication, less hierarchical \\
\hline Motivation of people & $\begin{array}{l}\text { Rewards and punishments tied to } \\
\text { job performance }\end{array}$ & $\begin{array}{l}\text { Deep desire to be appreciated and } \\
\text { to be part of a winning team }\end{array}$ \\
\hline People follow because & $\begin{array}{l}\text { Management controls and provides } \\
\text { clear direction }\end{array}$ & $\begin{array}{l}\text { Shared vision and understanding of strategic } \\
\text { intent }\end{array}$ \\
\hline
\end{tabular}

management approach guides personnel behavior towards achieving overall organization goals. An example might be a machine shop where individual machinists are essentially extensions of their machines and are expected to achieve certain quotas during each work shift. Salary bonuses might be offered for surpassing quantity and quality production quotas, while inferior performance might be dealt with through loss of benefits or even employment. Such a directive approach may be appropriate in some instances, but it does not fit the style expected by knowledge workers in research organizations. Yet, all too often university selections for leadership positions are based solely on reputation as an outstanding scholar (clearly a necessary condition) without consideration of their management experience or leadership potential. The outstanding scholar might have had great success with a directive approach in supervision of graduate students, but in many instances, for example with a new department head or research institute director, a transactional approach is instituted with predictably poor results over time. Recent studies, such as Malik, Danish, and Munir (2012) and Ismail, Mohamed, Sulaiman, Mohamad, and Yusuf (2011), have shown that the transformational model is more suitable for the university environment.

A variant on the transformational model which has proved quite applicable to organizational change is the adaptive model of Heiftiz (2006). In this model a distinction is made between the kinds of problems leaders routinely face. One kind of problem deals with those for which there are known solutions that can be addressed through current management structures and work processes. The other class requires an adaptation or change in beliefs, priorities, habits, and sometimes even loyalties. In this model, leadership is not situational but process focused, and the role of personal courage and risk taking is highlighted. Heiftiz describes actionable ways to lead and solve adaptive problems, such as the conduct of path finding experiments to guide organizational learning and to build support. Randall and Coakley (2007) has reviewed the applicability of this model to the university setting.

Recently, Kotter (2012) has contributed new ideas to his oft cited change management model that relate to both adaptive leadership and innovation. He describes the value of an "organization within the organization" to prototype new processes and practices and to serve as emissaries to the rest of the organization to motivate change. The ideas expressed are similar to practices pursued by large organizations like Whirlpool, Proctor 
and Gamble, and other Fortune 500 companies that have protected innovation venues outside their business units where disruptive concepts can be explored. Such practices are well codified in the innovation literature, for example in HBR (2005).

In parallel with the body of work in leadership models, there is a vast body of work on the behaviors and styles of successful leaders. For the purposes of this work, the servant leadership style is chosen as directly applicable. George (2007) describes this style from his own personal perspective of leading a Fortune 500 company. Collins (1996) also described this style of leadership, what he calls Level 5 leadership, as one of the distinguishing features between good and great companies. Kouzes and Posner (2002) define 5 behaviors that comprise the servant style: model the way, inspire a shared vision, challenge the process, delegate to others, and encourage the heart. More recently, Grant (2013) has shown the servant style combined with a focus on outcomes can lead to incredible success. Linden, Wayne, Zhao, and Henderson (2008) have shown that a servant leadership style and the social connections and exchanges it enables are as important as incentives and authoritative positions in enabling a focus on desired outcomes. They also show that the hiring of others to leadership positions who subscribe to or are willing to adopt the servant leadership style further enhance an organization's ability to achieve desired outcomes. Complementing the leadership models are the individual styles and behaviors exhibited by successful leaders. Şen, Kabak, and Yanginlar (2013) has proposed a model for courageous leadership that integrates many of the concepts of adaptive leadership and the servant style based on the characteristics of famous leaders such as Mahatma Gandhi and Martin Luther King, Jr. Another such leader, Ivan Allen, Jr., the former mayor of Atlanta, Georgia (USA) during the 1960s, is memorialized through the Georgia Tech annual award for leadership based on social courage. Seemiller (2013) has sought to capture the competencies expressed in the major leadership models and provide them in a guidebook indexed by career goals. This work, targeted for university students to help master leadership development skills needed for job preparation, is an interesting means for sharing leadership competencies.

A leadership model published by the Ross College of Business at the University of Michigan, published in DeRue, Spreitzer, Flanagan, and Allen (2013), integrates many of the transformational and adaptive leadership model concepts with the behaviors cited in the servant style. The motivation is to facilitate the creation of leaders within a university who seek to "make a positive difference in the world" and to support others. For the purposes of this work, this model is augmented to include the focus on organizational adaptation addressed in Cross (2013a) and to include an explicit focus on strategic intent. Zinni (2009) describes strategic intent as a statement of vision and strategy by senior leadership that is so clear and compelling that everyone in the organization can easily understand the role they serve in fulfilling the vision and strategy. Zinni further describes the role of senior leadership in being proactive and in anticipating future needs and opportunities as a critical aspect of enabling a shared sense of urgency. Influencing and enabling a culture of innovation and change tolerance within an organization is based on many of the leadership concepts described. The model is shown in Fig. 1 and developed further in the next section where the research strategy and leadership principles of the Georgia Institute of Technology are used as an example.

\begin{tabular}{lcl}
\multicolumn{3}{c}{$\begin{array}{c}\text { Achieving Results } \\
\text { (measurable) outcomes expected of the organization }\end{array}$} \\
\hline Serving Others & Building Community & Improving Culture \\
Model expected behavior & Create shared vision & Seek effectiveness \\
Listen actively & Build positive relationships & Improve continuously \\
Think boldly & Pursue inclusive excellence & Foster healthy competition \\
Act courageously & Facilitate interdisciplinary teams & Experiment often \\
Encourage and mentor constantly & Provide incentives & Learn from failures \\
Be accountable & & Celebrate successes \\
\hline Strategic alignment - vision, strategy, mission, and values & \\
\hline
\end{tabular}

Fig 1: Georgia Tech Research Leadership Model (GT-RLM) 


\section{OVERVIEW OF THE GEORGIA TECH LEADERSHIP MODEL (GT-RLM)}

Georgia Tech was created in 1885 to develop an educated cadre of technical leaders to support industry growth in the southeastern United States. It consists of six colleges, an applied research institute, and an economic development organization that includes a state-wide incubator and extension services for small to medium enterprises throughout the State of Georgia. The Institute includes support organizations that handle contracting and licensing, facilitate management, finances, human resources, and other support services. Fiscally, the Institute's budget is supported by the State of Georgia; tuition; sponsored research contracts with federal, state, and industry organizations; and philanthropy. A new strategic vision (Peterson, 2009) provides a 25 year roadmap for propelling the Institute forward in education, research, innovation, international programs, and internal processes. One focus in the vision is to align all research and economic development activities in order to significantly increase both the reputation of its research and its impact in driving a regional innovation ecosystem. Today, Georgia Tech is recognized as one of the top research universities in the world as published in Reuters (2012). It includes the largest engineering college in the United States. Its innovation ecosystem has been described in Cross (2012) and Breznitz (2012). Georgia Tech's sponsored research awards have increased $12 \%$ per year over the past four years and commercialization has also advanced significantly (e.g., a 7x increase in start-ups). Major international corporations (e.g., AT\&T, General Motors, Panasonic, ThyssenKrupp) have recently opened innovation centers on or in close proximity to the campus. The components of the Georgia Tech Research Leadership Model, the GT-RLM, are discussed next.

\section{Strategic intent}

As previously defined, strategic intent is an explicit statement of vision and strategy from senior leadership that guides all work efforts within the organization. The strategic intent for the Georgia Tech research enterprise follows.

Research at Georgia Tech is led by faculty, powered by ideas, and supported by professionals. We seek to create synergy between our breadth and depth in discovery-focused and applied research coupled with our deployment expertise. The EVPR Office exists to support and celebrate all research with a concurrent focus on pursuing transformational interdisciplinary research, creating influential thought leadership platforms, strengthening collaborative partnerships, and maximizing societal and economic impact. The work of the office is guided by a bi-annually updated operations plan that is informed by faculty and administrators.

Research is organized into core research areas and focused on grand challenges. Grand challenges are futuristic system descriptions that excite and motivate communities of researchers to work together to achieve some seemingly impossible capability. The key processes that create synergy between discovery, application, and deployment involve supporting curiosity, experimentation, and maturation. Each plays a key role in providing a bridge between two of the key research processes. The research strategy is further discussed in Cross (2013b). For the purposes of this paper, the leadership practices based on the GT-RLM are now discussed.

\section{Core values}

Core values describe immutable beliefs held by the people of an organization. At Georgia Tech the core values are integrity, excellence, impact, innovation, entrepreneurship, leadership, and community. They are summarized in Table 2. These values guide the actions of leadership in implementing strategy and in supporting work. Often there is a difference in an organization between stated values and real values. A key aspect of leadership is being faithful to the organizational values in word and deed. The GT-RLM research model includes four practice areas that provide a linkage between strategic intent and core values and focus on providing an environment where individual faculty and students are well supported, and where creativity and curiosity driven thought can co-exist, thrive, and synergistically benefit application and deployment activities. The core values and the practice areas of the servant leadership model put emphasis on empathy, courage, innovation, and outstanding accomplishment. Each practice area is discussed in the following subsections: Serving Others, Building Community, Improving Culture, and Achieve Results. 


\section{Table 2: Core Values of Georgia Tech}

\begin{tabular}{|l|l|} 
Georgia Tech Core Value & Definition \\
\hline Integrity & Honesty, high ethical standards, openness, transparency \\
\hline Excellence & High academic standards, embrace change, continuous improvement \\
\hline Impact & Improve human condition, solve hard global problems \\
\hline Innovation & Push boundaries, nurture curiosity within an interdisciplinary approach \\
\hline Entrepreneurship & Promote an enterprising spirit within students, faculty, and staff \\
\hline Leadership & Enhance thought leadership, prepare others to lead \\
\hline Community & Welcoming environment, mutual respect, celebrate diversity \\
\hline
\end{tabular}

\section{Serving others}

The first, and arguably most important, practice area of the GT-RLM consists of six attributes necessary for the successful research leader. These are summarized in Table 3. While individual personalities may and do vary from introvert to extrovert, personal credibility must be established. The leader must model and "do what she says she will do" making decisions in the best interests of the people and the organization. The leader needs to reflect the desired behaviors, consistent with core values, in her decisions and actions. Accessibility and regular communication are important, but too often a new leader spends his time talking about what she believes needs to be done rather than inviting input from others. Bill Marriott, the CEO of the Marriott Hotel Corporation, tells a story from very early in his career when he found himself at the home of a family friend who was entertaining President Eisenhower for a holiday weekend as described by Bryant (2013). President Eisenhower earnestly asked Marriott several questions and showed genuine interest in his answers. Since that time, Marriott has spent time walking the halls of his hotels and asking all within the organization their opinions about how to achieve the company's vision and strategy. The successful leader also thinks boldly. Earlier in his career, the lead author was a co-principal investigator (co-PI) with a neurosurgeon on a telemedicine project whose personal motto was, "Progress begins when you deny the present concept." This phrase encourages, indeed forces one to think of new ways to better support research and to master integrative thinking where the pros and cons of two or more competing ideas are fused, resulting in a bold, new idea. Allio (2003) describes practices to develop integrative thinking skills. Often these ideas will be risky to pursue. Hence, a successful leader must act with courage and conviction to take risk and to encourage others to do so, too. In service to others, the leader is also a mentor and teacher who exudes patience and encouragement. Research is an exciting endeavor, but it is also hard work and people can become discouraged easily. Lastly, the leader should practice personal accountability both in writing and in face to face personal meetings to facilitate information sharing and to obtain feedback. These six behaviors can be developed through practice and are necessary for successful support of the research enterprise. New leaders at Georgia Tech are selected both because of their research competence, but also because they have demonstrated these traits and a willingness to improve their mastery of them.

As an example, the lead author experienced such a leader in his initial encounter with Allen Newell in 1983. Professor Newell was one of the founders of the field of artificial intelligence and is also credited with fundamental discoveries in cognitive science. Having won the ACM Turing Award in 1975 and extremely busy in his position at Carnegie Mellon University, he really did not need to not attend a poster session during an international conferences late one afternoon with fledgling doctoral students. But he did. $\mathrm{He}$ showed genuine interest in the work presented and treated the students as respected peers. He offered helpful suggestion that upon personal reflection, showed both deep insight and bold thinking about how the research could be further developed. 
Table 3: Serving Others Practice Area

\begin{tabular}{l|l|}
\hline Attribute & Description \\
\hline Model the way & Be authentic - trust dependent on integrity; beliefs/actions reflecting core values \\
\hline Listen actively & Remember any stakeholder may have a better idea than you \\
\hline Think boldly & Deny the present concept and explore underlying assumptions and consequences \\
\hline Act courageously & Give permission to take risk; facilitate a culture of experimentation \\
\hline Encourage and mentor constantly & Show genuine interest, look for 'teaching' moments while helping \\
\hline Be accountable & Be open to and seek critical feedback \\
\hline
\end{tabular}

The lead author experienced such a leader in his initial encounter with Allen Newell in 1983. Professor Newell was one of the founders of the field of artificial intelligence and is also credited with fundamental discoveries in the field of cognitive science. Having won the ACM Turing Award in 1975 and extremely busy in his position at Carnegie Mellon University, he really did not need to not attend a poster session late in the afternoon of a conference in artificial intelligence where there were few attendees other than the graduate students. But the point is, Allen did attend, even though he seemed to go unrecognized at first. Completely unpretentious, he humbly introduced himself to the lead author, listened carefully and with genuine interest to the ideas being presented, then gently encouraged all of the students to "think bigger" or more boldly. In a later conversation, some of Newell's graduate students said that within his research group he held himself accountable to the same high standards he expected of others and always treated his students with respect. Not content to just pursue fundamental research, Professor Newell had a burning passion to see research results applied for societal good. He encouraged one group member, John McDermott, to pursue an early and very successful expert system as described in McDermott (1982). Newell's leadership reflects the six attributes of the servant leader and which he used successfully to build community among his students and colleagues.

\section{Building Community}

A key aspect of successful leadership within the research university is to build a sense of community internally and to strengthen partnerships with other entities necessary to successful research. These communities must believe they "own" the problems they are trying to solve and that they have freedom to pursue innovative approaches to solving them. At Georgia Tech, communities are organized around core areas of research that include biomedicine, health systems, manufacturing, materials, electronics and nanotechnology, and energy systems. The five attributes of this practice area are summarized in Table 4. First, it is imperative to build positive relationships by creating a climate of open communication and trust with stakeholders across the university. This can be done through regular communications (e.g., email posts, surveys, town hall meetings, informal meetings with faculty) where active listening is practiced visibly and often. One intent of the regular email posts is to show how ideas submitted by faculty are enacted. The next two leadership skills, creating shared visions and promoting interdisciplinarity, are closely related. At Georgia Tech, task forces are commissioned on a regular basis to define a shared vision to a hard global problem (e.g., sustainability in the future city, improving the quality of life for the elderly) in which faculty define both a vision, often encapsulated as a grand challenge statement, along with a roadmap and proposed plan for pursuing the problem. As an example, Georgia Tech's new interdisciplinary Institute for Materials was announced in June 2013 to focus on computationally designed materials. A faculty led task force held offsite meetings with over 75 materials researchers and an exciting plan was created, one that garnered attention by the White House and in fact, was announced in a White House press release. The materials task force also shows the value of empowering teams to pursue their visions. The task force had the authority to make decisions about its future, though at times it was encouraged to take more risk. "Giving permission to take risk" is a recurring theme across many of the leadership skills. Such task forces have benefited from a deliberate recruitment of divers representation based on scholarship area as well as gender, ethnicity, and other demographic descriptors to encourage bringing multiple points of view and life experiences to discussion and planning. Lastly, it is necessary to provide incentives. At Georgia Tech this includes purposeful recognition of faculty leadership (e.g., annual awards for research accomplishment that includes leading teams), provision of discretionary funds to faculty and administrative units supporting faculty, and consideration in the promotion and tenure process. The leadership skills discussed here for internal team 
building are also applicable to external partnerships with sponsors and other stakeholders exemplified by Georgia Tech's strategic partnership with Children's Healthcare of Atlanta, the largest pediatric care organization in the United States. The community building leadership skills have been applied over the past two year period to build a very strong and trusted relationship where teams of faculty and clinicians work together to address grand challenges ranging from implants that can grow with a child, to finding a cure of single defect diseases like cystic fibrosis, to significant reduction in the cost of pediatric care (the State of Georgia covers approximately $40 \%$ of such care to over 1 million children).

Another example of a leader proficient in building community is Professor Robert "Bob" Nerem. Professor Nerem arrived at Georgia Tech in 1987 with the goal of establishing an interdisciplinary research focus in biomedicine. Interdisciplinary pursuit within the research university is often difficult due to academic boundaries between disciplines that discourage collaboration (e.g., promotion and tenure decisions may be based on publication in domain specific archival journals that do not typically include interdisciplinary work). But Bob created an exciting vision of the future of regenerative medicine that required simultaneous advances in several scientific and engineering disciplines. He worked tirelessly and convinced a key donor to help fund the development of a new laboratory building devoted to the interdisciplinary pursuit of biomedicine where work is organized in research neighborhoods allowing faculty and students from various departments to meet in teams aimed at solving grand challenge problems and where all work on a first name basis helping to promote equality and to incentivize creative thought. The results were and continue to be spectacular, as noted in a recent National Research Council report edited by Connelly and Sharp (2009). Like Allen Newell, Bob Nerem built community by establishing positive relationships and forming teams to create shared visions.

Table 4: Building Community Practice Area

\begin{tabular}{l|l}
\hline Attribute & Description \\
\hline Build positive relationships & Communicate frequently, be positive, show genuine interest in others \\
\hline Create shared visions & Envision the future; enlist others by discussing their enabling role \\
\hline Build positive relationships & Communicate frequently, be positive, show genuine interest in others \\
\hline Pursue inclusive excellence & Seek involvement of everyone regardless of gender, ehtnicity, etc. \\
\hline $\begin{array}{l}\text { Facilitate interdisciplinary } \\
\text { teams }\end{array}$ & $\begin{array}{l}\text { Charter task forces to explore hard problems that include many disciplines/groups; } \\
\text { encourage bold thinking and shared decision making }\end{array}$ \\
\hline Provide incentives & \begin{tabular}{l} 
Ensure appreciation is shown for earnest effort \\
\hline
\end{tabular}
\end{tabular}

\section{Improving Culture}

As mentioned in the beginning of the paper, research universities are called upon to accomplish expanded missions and this requires them to adapt and to embrace cultural change. The leadership skills for this focus are summarized in Table 5 and developed in more detail in Cross, (2013b). Key changes required in the Georgia Tech culture are 1) the pursuit of a concurrent strategy to support leading edge research in concert with increasing economic development impact, 2) the movement from the typical single PI model to working in interdisciplinary teams, and 3) an ongoing change in the support functions of the Institute based on a renewed service mentality and a systems approach to serving those conducting research. For example, the contracting and licensing functions have adapted, becoming more service and innovation oriented from a past stance on compliance. While compliance is a necessary and critical function, the people assigned to the contracting and licensing functions accepted the challenge to provide more industry and faculty friendly services. They pursued process improvements in the contracting process which they seek to continuously improve. As part of a faculty task force on innovation, they adopted an approach to experiment with new and creative approaches for supporting faculty in pursuit of start-up companies. They learned from some missteps, but also have celebrated their successes. The criticality of a faulty tolerant culture is explored more in Farson and Keyes (2002). All research leaders are encouraged to regularly think how work can be done better in support of faculty. Competitions are used regularly to guide selection of proposals for internal research funding (called seed grants and used primarily to "seed" or initiate new work where initial research results and data are required for significant external awards). In addition costs centers have been created around large and expensive equipment and clean rooms to facilitate shared use, provide services to industry, 
and to share costs. Cross (2013b) provides an illustration of improving culture as well as achieving results as discussed in the next section.

Table 5: Improving Culture Practice Area

\begin{tabular}{|l|l|}
\hline Attribute & Description \\
\hline Seek effectiveness & Keep asking what can be done better \\
\hline Improve continuously & Encourage everyone to improve how work is done \\
\hline Foster healthy competition & Use merit selection process for seed grants and equipment \\
\hline Experiment often & Admit we don't know all answers, discover them \\
\hline Learn from failure & No fear of failure as long as something valuable is learned \\
\hline Celebrate success & Give credit to others and recognize them \\
\hline
\end{tabular}

\section{Achieve Results}

Lastly, leadership skills are indeed related to expected outcomes. This practice area is customized to meet the outcomes desired by the organization. Hence the attributes shown here are reflective of the organization's overall objectives. The successful leader focuses on these outcomes when she considers the leadership skills undertaken in service to others, building community, and changing culture. Arguably the most important is enhancing scholarship and the reputation of the faculty. Scholarship is enhanced not only through pursuit of research, but by using research results and the research infrastructure itself to enhance education. Innovation competitions as part of student capstone courses are supported by industry. In these courses, students explore disruptive concepts on behalf of local industry partners. As Georgia Tech's interdisciplinary focus becomes more prominent, new thought leadership platforms have been created such as the previously mentioned materials initiative. A reputation for defining and solving hard problems has increased, for example through the publication of a national robotics roadmap. Significantly, Georgia Tech is recognized increasingly for its economic development impact as a partner in facilitating the transition of research results into industry use. All of this has helped increase and diversify external support for research. While the leadership attributes in this section also deal with measurable outcomes, the successful leader keeps in mind the desired organization outcomes, and related plans to achieve them, in concert with the leadership focus areas related to serving others, building community, and changing culture. The leadership practices are summarized in Table 6 .

\section{Table 6: Achieving Results Practice Area}

\begin{tabular}{l|l} 
Attribute & Description \\
\hline Enhance scholarship & Seek ways to enhance scholarship, improve education \\
\hline Create thought leadership platforms & Position faculty into positions of influence within their communities \\
\hline Define and solve hard problems & Gain a reputation as the place that sets the research agenda \\
\hline Support adoption across the ecosystem & Facilitate translational research and transition to use \\
\hline Increase and diversify the sponsorship base & Grow the resource base to support research
\end{tabular}

\section{DISCUSSION}

The leadership model presented and leadership practice areas are used in the selection and development of research leaders at Georgia Tech. Continuous improvement of one's leadership abilities is an ongoing process. Within the university, the Institute of Leadership and Entrepreneurism (ILE) within the Georgia Tech Sheller College of Business supports a community of leadership practice involving over 75 faculty and administrators. Leadership competencies are discussed and peer mentoring is used to help develop leadership capabilities. ILE conducts a leadership roundtable that consists of a weekend retreat for small groups of faculty as well as networking sessions throughout the year. This is a primary means through which younger faculty are introduced to leadership principles. For the past two years a variant of this offsite has been provided to newly tenured faculty. This community of practice $(\mathrm{CoP})$ is an excellent example of the situated learning method first developed by Wenger (1998).

To expand the impact of this CoP to other universities, and to further develop and enhance the leadership model discussed herein, current research is exploring the usefulness of an online repository of leadership 
stories. Story telling is a well-recognized means to support peer learning and in fact is advocated as a critical capability by many large institutions seeking to develop leadership skills of their senior staffs. Smith (2012). A new area of applied research is the development of an online repository of "leadership stories" based on the focus areas briefly described in this paper. Interested members of the research community are encouraged to submit stories to the author for dissemination for inclusion based on the practice areas briefly described in this paper. While perhaps new in the context of research leadership, this is not a new idea. Mahato (2011) provides a moving account of how Leroy Sievers, a long time journalist and television correspondent, blogged about his struggle with cancer. The online stories he shared "not only enables engaged and communal conversations about illness, pain, grief, and mourning but also moves counter to our culture's easily digestible and repressive approaches to these life matters." In the same vein, a web site entitled PatientsLikeMe as described by Wicks (2010) has become an incredibly useful resource for patients (and care providers, family, and friends) to share experiences prompted which not only helps emotionally with coping with a serious ailment but provides a world-wide online resource to share ideas about improved therapy and treatment.

Storytelling is central to learning and communicating. Through storytelling we reflect on our experiences and communicate the emotional and intellectual content and quality of our experiences. Stories both connect and divide us. Through storytelling we capture alternative perspectives and learn to think differently and critically. While at the same time, stories help us see what's common in our experiences, enabling us to relate to one another and build community. Storytelling and listening are also central to ethical learning and reasoning especially considering that values and principles can become abstract and detached from matters of everyday practice. The examples used throughout this paper are illustrative.

The creation of a forum for collecting and sharing leadership experiences is experimental and exploratory in nature. It builds on the hypothesis that these stories can be put to various uses and serves a range of purposes. Such a forum, for example, may serve as a useful tool for leaders to draw upon as they encounter problems and engage with issues in their everyday practice. It may also be valued as a platform for voicing varied perspectives and reflections on the stated values thus enabling leaders to think differently about what such values may entail in practice. Lastly, and perhaps most importantly, it serves as a starting point for community building and gathering around the shared problems and concerns of leadership. When models, theories, and known solutions fail, it is great to know that you can reach out and connect with people who are experiencing and being challenged by similar situations and problems. Much like any other leadership initiative the success of such a tool depends greatly on how it connects with the ecology of other resources and programs, and the mechanisms by which it is sustained and evolved both as a resource and a virtual community.

Work is underway at Georgia Tech to create an online repository of leadership stories. A web site has been created and it will go live later in 2014. Those who wish to contribute to the leadership model described in this paper and to contribute to and benefit from the experiences of other leaders are invited to contact the lead author.

\section{SUMMARY}

The research university is expected increasingly to not only support research and education within its university, but to drive its regional innovation ecosystem. This often means adapting to new internal and external realities. Leadership must guide the adaptation and inspire the need to change with a sense of urgency. The paper argues that an adaptive model and a servant style are most effective in providing a leadership process that is shared across the organization in support of faculty and research goals. Georgia Tech has adopted a model of leadership called the Georgia Tech Research Leadership Model that encodes leadership principles into four practice areas: serving others, building community, changing culture, and achieving results. With each practice area, specific leadership attributes are described. Leaders are chosen based on a predisposition to these principles, along with their demonstrated research competence. Mentoring and leadership development are expected from everyone in a leadership position. Use of this model is a major way in which Georgia Tech is pursuing its strategic vision. 


\section{REFERENCES}

Cross, S. (2013). A Model to Guide Organizaiton Adpatation, Proceedings of the 2013 IEEE International Technology Management Conference \& 19th ICE Conference, The Hague, Netherlands, in press.

Katz, B. and Bradley, J. (2013). The Metropolitan Revolution: How Cities and Metros Are Fixing Our Broken Politics and Fragile Economy. The Brookings Institution, Washington D.C., USA.

Clark, J. (2013). Working Regions: Reconnecting Innovation and production in the Knowledge Economy. Routledge: New York City, New York, USA.

Hage, J. (2011). Restoring the Innovation Edge. Stanford University Press. Stanford, California, USA.

Lopez, S. (2013). Making Hope Happen, New York: Simon and Schuster.

Charan, R., Drotter, S., and Noel, J. (2011). The Leadership Pipeline: How to Build the Leadership Powered Company. San Francisco: John Wiley \& Sons.

Mailk, M., Danish, R., and Munir, Y. (2012). The Role of Transformational Leadership and Leader's Emotional Quotient in Organizational Learning, World Applied Sciences Journal. 16:6, 814-818.

Ismail, A., Mohamed, H., Sulaiman, A., Mohamad, M., and Yusuf, M. (2011). An Empirical Study of the Relationship between transformational Leadership, Empowerment and Organizational Commitment.

Business and Economics Research Journal. 2:1. 89-107.

Charan, R., Drotter, S., and Noel, J. (2011). The Leadership Pipeline: How to Build the Leadership Powered Company. San Francisco: John Wiley \& Sons.

Heifetz, R., Linsky, M., Grashow, A. (2009). The Practice of Adaptive Leadership: Tools and Tactics for Changing Your Organization and the World, Cambridge MA: Harvard Business Press.

Kotter, J. (2009). Accelerate! Harvard Business Review, 87:11, 44-58.

HBR Innovation Handbook: A Roadmap to Disruptive Growth, (2005). Cambridge MA: Harvard Business School Publishing, Product Number 9580.

Randall, L. And Coakley, L. (2007). Applying Adaptive Leadership to Successful Change Initiatives in Academia, Leadership and Organization Development Journal, 28:4, 3250335.

George, B. (2007). True North: Discover Your Authentic Leadership. San Francisco (USA): John Wiley \& Sons.

Collins, J. (2001). Good to Great: Why Some Companies Make the Leap and Others Don't. New York (USA): Harper Business.

Kouzes, J. and Posner, J. (2002). The Leadership Challenge, San Francisco: Jossey-Bass.

Grant, A. (2013). Give and Take: A Revolutionary Approach to Success. New York: Viking.

Liden, R., Wayne, S., Zhao, H, and Henderson, D. (2008) Servant leadership: development of a multidimensional measure and multilevel assessment. The Leadership Quarterly, 19:2, 161-177.

Şen, Kabak, and Yanginlar, G. (2013). Courageous Leadership for the Twenty-First Century. ProcediaSocial and Behavioral Sciences. 75:91-101. presented at the $2^{\text {nd }}$ International Conference on Leadership, Technology and Innovation Management.

Seemiller, C. (2013). The Student Leadership Competencies Guidebook: Designing Intentional Leadership Learning and Development. Jossey-Bass (Wiley Publishing), San Francisco, California (USA).

DeRue, D., Spreitzer, G., Flanagan, B., and Allen, B. (2013). Developing Adaptive Leaders for Turbulent Times: The Michigan Model of Leadership, The European Business Review. www.europeanbusinessreview.com/?p=8950.

Kouzes, J. and Posner, J. (2002). The Leadership Challenge, San Francisco: Jossey-Bass.

Zinni. T. and Koltz, T. (2009). Leading the Charge, New York: Palgrave McMillan. 
Peterson, G.P. (2010). Designing the Future, Georgia Institute of Technology. Atlanta, Georgia. www.gatech.edu/vision

Reuters. (2012). Top 50 Engineering and Technology Universities. www.timeshighereducation.co.uk/worlduniversity-rankings/2012-13/subject-ranking/subject/engineering-and-IT

Cross, S. (2012). Strategic Considerations in Leading and Innovation Ecosystem, GSTF Journal on Business Review. 2:3. 104-109.

Bresnitz, S. (2012). Breznitz, S. The Engaged University, The Journal of Technology Transfer, 2012, 37:139157.

McDermott, J. (1982). R1: The Formative Years. AI Magazine. 2:21-29.

Connelly, T. and Sharp, P. (Co-Chairs). (2009). New Biology for the 21st Century: Ensuring the United States Leads the Coming Biology Revolution. National Research Council. Washington DC (USA), National Academies Press.

Allio, R. (2003) A Systemic Approach to Innovation. Strategy and Leadership. 31:3, 19-26.

Bryant, A. (2013). What Eisenhower Taught Me About Decision-Making, The New York Times. 26 May (Business).

Cross, S. and Wang, B. (2013). A Systems Approach to a Research University's Research and Innovation Strategy, Proceedings of the International Institute of Industrial Engineering Conference, Istanbul Turkey, in press.

Farson, R. and Keyes, R. (2002). The Failure-Tolerant Leader, Harvard Business Review. 80:8, 64-73.

Wenger, E. (1998). Communities of Practice: Learning, Meaning, and Identiy. Cambridge University Press. Cambridge UK.

Smith, P. (2012). Lead with a Story: A Guide to Crafting Business Narratives That Capitvate, Convince, and Inspire. AMACOM (American Associationof Management). New York City, New York, USA.

Mahato, M. (2011). Virtuous Community: Online Storytelling in Leroy Sievers's My Cancer. Storytelling, Self, Society. 7:211-228.

Wicks, P., Massagli, M., Frost, J., Brownstein, C., Okun, S., Vaughan, T., Bradley, R., Heywood, SJ., (2010). Sharing Health Data for Better Outcomes on PatientsLikeMe, Journal of Medical Internet Research, 10:2, http://www.jmir.org/2010/2/e19/. 